Article

\title{
Existence and Resistance: The Social Model of Community Education in Ireland
}

\author{
Maeve O'Grady \\ School of Lifelong Learning \& Education, Waterford Institute of Technology, X91 K0EK Waterford, Ireland; \\ mogrady@wit.ie
}

Received: 30 September 2018; Accepted: 15 December 2018; Published: 18 December 2018

\begin{abstract}
Community education in the Republic of Ireland exists in several forms and in several sites. This article draws on two qualitative research projects in community education to identify the practices of the social model of community education that link them. The context of the research is the impact of policy changes as experienced by the practitioners and providers. The social model can be spoken of in different terms, depending on the practice of the speaker; it can be a process model of curriculum, critical literacy, or feminist emancipatory pedagogy. The article describes different discourses of practice and considers how practitioners could, while differentiating aspects of their practice, find common ground and resist the erosion of adult education for social justice by the state's drive for vocational education for the labour market.
\end{abstract}

Keywords: social model; community education; neoliberalism; resistance

\section{Introduction}

Community education involves working with the most economically and socially disadvantaged groups in non-formal and formal sites (Lovett 1975). Representing a community education group has taken me into higher education, where my work involves teaching adult and further education tutors. Critical theory underpins my particular perspective, because it highlights the intersectionality of class, gender, race, and other factors that impact on people, especially in relation to their learning and development opportunities. Merrill and Fejes (2018) noted the concern in adult educational research about the identity of working-class men and women in middle-class higher education and adult education institutions. This synthesis of two research projects focuses on adult education sites that are linked by a social model of community education that minimises identity conflicts.

The two research sites originated as grassroots responses to the educational disadvantage experienced by adults in the 1980s in the Republic of Ireland; both sites became professionalised as a result of building their relationship with the Irish state funding their work. The State then proceeded to respond to calls to make formal education more accessible, and the consequent policy developments provided an infrastructure for adult education, which was framed as 'Further Education'. Both sites are now subject to changed accountability demands that are experienced as challenging. The rationale for the new policies may appear to be reasonable, but it is ideologically driven, and threatens to ignore or suppress adult education for social justice in favour of vocational education for the labour market.

This article describes the context in which both women's community education and the adult literacy movement developed through different relationships with the Irish state, and the more recent policy developments that prompted two organisations to reconceptualise their mission and ethos. Although the two sites of practice have a relationship with separate government departments, both are affected by the state's neoliberal understanding of the purpose of lifelong learning. The first type of community education practice that is dealt with in the article relates to women's community 
education. This draws on ethnographic research with a women's community education organisation that engaged in a reflexive exercise in an attempt to redefine their mission in a new policy environment (O'Grady 2018). The second type of community education is adult literacy provision, drawing on grounded theory research undertaken with tutors who were interviewed about their aims and teaching methodology (O'Grady and Byrne 2018). The agency of adult literacy tutors is visible in their discussion of their pedagogy, as the agency of a women's community education organisation is visible in its learning culture. The two research projects and the two types of practice have in common an understanding of Paulo Freire's theories about education. Freire's (1970) concepts provide an understanding of how a culture of silence is characteristic of mainstream educational systems that do not reflect people's lived experiences or values. Literacy education for Freire means generating and facilitating a space for adults so that they can reflect on their experiences and strengths, analyse how power works, and consider what action to take. The hidden curriculum of mainstream education is that it continues to make the oppressive practices of neoliberalism appear as if there is no alternative.

Both fields of practice at local and national levels work to reduce barriers to access, participation, and outcome for individuals and groups in the public sphere through education and development, however these are defined. The demand for the policy changes and the development of new structures for further education developed alongside accountability mechanisms and financial restrictions, which equality theorists have argued are a reflection of a 'care-less' neoliberal state (Lynch et al. 2012). The changes seemed to trigger a common crisis of identity amongst practitioners because of the perfect storm of a steady erosion of the equality infrastructure of the state and new managerialist policies that had been anticipated by many writers such as Finger and Asún (2001), Connolly (2008), and Murray et al. (2014). The need for the different areas of community education to reframe their practice and reconceptualise their mission for the 21st century is a reflection of the challenges of neoliberalism for adult education that have been anticipated by those writers.

\section{Context: 1980 s to 2000}

Ireland is a late-modernising country, inheriting an education system that had been owned by religious orders and left alone by the new state since being established in 1922 (Breen et al. 1990). The state supplemented, not supplanted, the provision that existed at that point (Curry 2003). The education system from 1922 to the 1950s could be described as reflecting Trow's (1974) elite stage of development, when the numbers in secondary school were relatively small, and the numbers going to university were smaller again. By the 1950s, Ireland was a failed economy, needing state intervention to stop the scale of emigration by raising employment levels. The policy solution in 1958 of bringing foreign direct investment to Ireland required an educated labour force. This was achieved by providing free second-level education, increasing the amount of places available in universities, and building new third-level regional technical colleges that enabled people to become qualified operatives, technicians, supervisors, and managers to meet the labour needs of industry. Characteristic of the massification stage of participation in higher education (Trow 1974), the state invested heavily in increasing the amount of places available, but the nature of third-level education stayed the same. Provision was for the full-time student, requiring a school leaver to proceed directly from upper second-level into third-level education. Adults could return to education as mature students on a full-time basis. Training was limited to apprenticeships, with some vocational provision availed of by workplace learners studying part-time (McGuinness et al. 2014). Extra-mural courses were provided by the adult education departments of universities as evening classes. Local vocational education committees (VECs) provided night classes for fee-paying adults.

Extra-mural courses and night classes attracted those who had the money for fees and a sense of confidence or entitlement. For working-class adults with low levels of educational qualifications, prospects were poor in relation to availing of third-level education. Adults in some occupations could be supported by their employers to avail to night classes and gain qualifications provided by United Kingdom (UK)-based organisations such as City and Guilds. Adults outside of such environments 
were provided for by non-formal provisions: voluntary adult literacy tutors worked with adults on a one-to-one basis, and women's self-help groups started to organise to take control of their own education and development, and worked to establish adult daytime education (Inglis 1994).

The slogan of the women's groups was 'no crèche, no class' (Inglis 1994), which reflected a key barrier to participation for women working at home in the Ireland of the 1980s. It also reflected a desire to participate more in the public sphere while engaged in private, domestic duties. This individualistic desire was evident, even though the philosophy was Freirean and feminist, based on feminist groupwork and social analysis. I was one of the participants who embodied it. This collective-individual tension is a feature that is evident to this day, and reflects the problem identified by Connolly (1997) that a Freirean vision of emancipation is problematic when it has to be mediated through an individualistic liberal discourse. The women's groups that formed had a vision of social change through collective action, but individual needs and goals had to be included as well.

By the end of the 1980s, groups were able to avail of grants from the Department of Social Welfare under 'The Scheme of Grants to Locally-Based Women's Groups' (Mulvey 1991). This scheme was then subsumed into the state's anti-poverty Community Development Programme, with aims of empowering community groups in disadvantaged areas to represent themselves and take collective action on issues affecting them. The discourse of community development allowed the women's groups to use informal community education processes, and some groups made more formal arrangements with third-level institutions (Kelly 1994).

Connolly identified certain characteristics of the groups that used community education for social change purposes:

- Groups analysed their own educational needs, and organised courses accordingly

- The focus was on being agents of change in their own communities and in wider society

- Discussing individual experiences in a group enabled common or structural features to be identified, and implications to be considered. Women bring their own experiences to the discussion, and "these are interpreted in social and cultural terms, rather than individualistic or private ones" (Connolly 2008, p. 7).

\section{Adult Literacy}

Voluntary literacy tutors formed The National Adult Literacy Agency (NALA) in 1980, and in a relationship with the Department of Education, developed policy and good practice in adult literacy (Hamilton et al. 2001). The department made funding available to adult literacy schemes and appointed Adult Literacy Organisers throughout the VECs in the country. The Adult Literacy and Community Education (ALCE) funding was to pay tutors working with groups; tutors working with individuals on a one-to-one basis did so as volunteers.

In 1999, NALA developed a quality framework for adult literacy that guided tutors towards a learner-centred approach to provision. The five principles for adult literacy work that were provided in tutor training reflected a Freirean focus on social issues; for example:

"Literacy learning may lead individuals and groups to relate their own experiences to wider social issues. They may then wish to become involved in local or national action for social or educational change" (NALA 2008, p. 6).

\section{Adult Educational Disadvantage}

By 2000, the scale of adult educational disadvantage was recognised, along with the responses to it by adult literacy and women's community education in the 'White Paper on Adult Education in an Era of Lifelong Learning' (Government of Ireland 2000). This recognised the role of independent women's community education. However, recognition did not mean resources. The promise of funds was restricted to the community education that was provided by VECs, such as the appointment of Community Education Facilitators, more money for adult literacy schemes, a fund for a 'Back to 
Education' initiative, and the establishment of an adult educational guidance service. The White Paper acknowledged the need for new structures to facilitate lifelong learning. Recognition of prior learning was promoted, but only in the chapter on workplace education (Government of Ireland 2000).

Ryan stated that the White Paper's promise to professionalise the Further Education and Training (FET) sector reflected lifelong learning discourse. Lifelong learning is used:

"... interchangeably with other terms that refer to education outside the formal school and higher education systems ... [that are] largely driven by the OECD and the European Union's use of the term in ways that no longer emphasised creating structures and institutions to meet the needs of the learner [and] instead focused on the learner taking courses to acquire skills to fill gaps in the labour market" (Ryan 2014, p. 171).

According to Papen (2005), there are different discourses of adult literacy, with the terms 'functional literacy' or 'basic literacy' reflecting a deficit view of the adult, and the solution to problems of poverty and social exclusion being the provision of basic literacy skills. The New Literacy Studies inspired by Freire, on the other hand, place the adult in a social and cultural context, with already existing informal literacy practices that may not be recognised by formal education. According to Crowther and Tett, the danger of viewing adult literacy as the acquisition of functional skills can "reinforce a deficit model of the learner and a remedial view of adult literacy provision" (Crowther and Tett 2011, p. 134); this is a critical literacy approach that incorporates attention on the "inequalities of power in everyday life", which is necessary to enable the learner to take action against oppressive structures by understanding the "constructed nature of life" (Crowther and Tett 2011, p. 135).

Recognising the existing literacy practices of an adult enables the tutor see that the adult literacy learner already has a wealth of knowledge and experience to bring to the classroom. Thus, this wealth model is a reflection of the view that the tutor has of the adult learner, and counteracts the deficit view of the adult as lacking.

\section{Could We Credit It?}

In the meantime, women's community groups established crèches, but access to qualifications remained a barrier in Ireland's highly-credentialised society, which was a feature noted by Drudy and Lynch (1993). The Combat Poverty Agency, Aontas (Ireland's national representative body for adult education), and the European Union's New Opportunities for Women Programme commissioned research in 1993 on the accreditation needs in the independent women's community education sector in order to highlight the policy deficit that impeded the mobility of women back into the workforce (Kelly 1994). Since the community development programme was funded by government departments other than Education, there was no sense that the Department of Education was addressing the accreditation issues of the independent community education groups. The findings enabled community education groups to link to the emerging further education structures and be seen as legitimate providers in their own right.

\section{What Happened Next?}

The White Paper (Government of Ireland 2000) identified a policy commitment to developing a new national qualifications framework that would be underpinned by principles of "access, transfer and progression" (www.qqi.ie n.d.). While new qualifications and certification structures were taking shape, and the arena of further education was expanding and being availed of by the independent women's community education organisations, changes were being made to the Community Development Programme that funded the groups. The underpinning goal of the programme of social inclusion was being narrowed to service delivery, and the state committed to fund only those organisations whose plans were aligned with state policy goals. The capacity-building of groups became limited to enabling groups providing services. Fitzsimons stated that these policy changes "have been framed in the context of neoliberalism, that is, that the only way to social cohesion, equality, 
and democracy is through serving the economy" (Fitzsimons 2017, p. vii). The programme funding that remained available to community education groups was for labour market activation purposes.

At the same time as the changes to community development and independent community education, the equality infrastructure of the state was annihilated (Lynch 2013). Starting before the financial crash of 2008, state agencies with responsibility for equality in employment, civil rights, traveller rights, and disability groups suffered cutbacks or closure. The support infrastructure for community development also changed radically, with local area-based partnerships replaced by a new local authority-controlled structure incorporating local development. The new Social Inclusion and Community Activation Programme (SICAP) programme is, according to Fitzsimons, using the rhetoric of community development, but enforces monitoring through the tightly-regulated reporting of measurable outputs (Fitzsimons 2017, pp. 149-50). The climate of fear and anger caused by the financial crash made it impossible for community education and development organisations to mobilise effectively against cuts.

More policy change affecting both adult literacy and community education came in 2012 when the difficulties caused by the lack of state control of existing provision justified the establishment of Solas, which is a funding agency that was formed to distribute and monitor education and training, and the amalgamation of the state training agency and the VECs into Education and Training Boards (ETBs). Further education became established as vocational education.

The Solas (2014) strategy for Further Education and Training (FET) stated that state funding of community-based education and training would no longer be distributed on a legacy basis, but would instead transition into competitive tendering based on targets and outputs. This would also involve private and community-based quality-assured organisations competing against ETBs. Monitoring and measurement would be rolled out. Measurement metrics are based on the idea of 'progression', meaning numbers completing certification and numbers gaining employment.

NALA's development of the fourth edition of its Guidelines for Good Adult Literacy Practice was triggered by the replacement of the VECs with ETBs, and the establishment of SOLAS as the education and training authority. It was timely to refresh and restate the rationale for adult literacy work and how it should be carried out (McHugh and Dolan 2012, p. 5). While initial tutor training teaches the Guidelines for Good Adult Literacy Practice, some of the principles may be neglected in the new context of practice. NALA then researched and produced a series of case studies on teaching adults that were compiled from interviews with experienced tutors willing to showcase their practice and provide a resource to other tutors (Byrne et al. 2014, 2016). I have been involved as a researcher since 2012 in interviewing adult literacy tutors, and analysing the data that has been collected.

\section{Impact on Adult Literacy Tutors}

Adult literacy schemes are now being asked to use the same SOLAS reporting templates as the rest of further education in order to facilitate data collection. Some tutors in my classes are concerned that the reporting mechanism reflects a behaviourist approach that threatens the philosophy of adult literacy, because it seeks outcomes only in terms of progression into employment or higher levels of formal education. They also report feeling under pressure to present certification to learners as mandatory instead of optional, as a failure of numbers to submit for certification may be judged adversely in a competitive tendering system.

\section{Impact on Women's Community Education}

One women's community education organisation needed to reconceptualise its mission of social change, which was originally defined in 1996, because of the new policy context and nearly 20 years of working with women with individual goals who did not relate to feminism. Given the transformation of community development into the service provision of state goals, and severe cutbacks in money available for staff pay, what was the organisation doing that was worthwhile? How did the provision of community education meet women's needs? An additional spur to reflection was the observation 
of transformations in participants and participants' own reporting of transformations that were not 'claimable' or recognised in any reporting mechanism. As in the case of adult literacy, what was demanded was numbers 'progressing' into the labour market. Funding was increasingly becoming contingent on offering certified modules using the National Framework of Qualifications (NFQ).

The concern of the founders, board members, and staff was that the mission was not a good fit in these new circumstances. As changes were required, it was important to define what was possible, what should be held onto and valued, and the implications for its mission of social change for women. Was it actually failing to activate the agency of working-class women to change society and oppressive structures?

The reader will notice that the women's community education research refers to 'participants', and the adult literacy research refers to 'learners': these are terms that are used in the different fields of practice.

\section{The First Research Project: The "Nothing Stuff"}

Using institutional ethnography (Smith 2005), I was able to be a fieldworker for four weeks, gathering data in the breaks between sessions and, when invited in to group sessions, asking questions when appropriate, and noting responses and observations. Smith (2005) argued that a 'sociology for women' is possible by using institutional ethnography to show the nature of the effect of societal structures on them, and their sense of agency in relation to taking action in their lives. Institutional ethnography requires a social map to be made: in this case, the social map of the organisation described its activities, the numbers of groups involved, the participative management structure, the crèche, and what participants and staff say about it. By this means, the influence and effects of wider societal structures can be identified, and the role of the learning culture of the organisation can be related to changes for participants.

A learning culture represents a field of practice with 'rules' that require a distinct way of being, or habitus. According to Bourdieu (2001), a field of practice generates its own way of being, its own habitus as a set of dispositions and preferences that guide actions. When exposed to a new field of practice such as a learning culture in a women's organisation, participants can practice a provisional habitus, by testing out a different way of being, and seeing if it suits them. However, habitus cannot be changed by cognitive means alone (Bourdieu 2001), so identifying the elements of the learning culture will tell what contributes to a sense of positive change for participants in a way that focussing on the content and processes of groups and class activities would not.

The following quotations illustrate how different the learning culture is for participants, and the impact of some of the practices:

"I was asked for my opinion. No one had ever asked me for an opinion."

"We learn we can solve issues by being part of a group."

"It's an effort to be here some days. Some days, it's more challenging. I like that you can just come, you don't have to talk or do anything you're not comfortable doing."

"I was invisible. I think that's changing now."

"Two years ago, I wouldn't have stood up for myself."

"I've never felt so well since I came on the course. I have a new lease of life, the way I see things, the way I deal with situations."

"You can only do this better (work with women) if you understand who you are."

"When you know what you want, no one can push you around."

"I don't feel intimidated in the small groups." 
The data identified features of the environment and the learning culture. A focus group of facilitators and staff reflected on the data and identified how they create the learning culture and understand the needs and lives of the participants:

"Society does not recognise for instance being a mother, and therefore doesn't allow your voice to be heard. But the group recognise this, and values the work you are doing, and that gives you the voice and the sense you are worth listening to."

"As women we have been conditioned to put ourselves at the bottom of the list, and what we do here is challenge each other to go against the conditioning."

"In the outside life, you wouldn't get an opportunity to say what you need in a peaceful manner."

"The knowledge that the space is safe empowers women to just be themselves."

"Sometimes the challenge is part of the support, [to] challenge the woman to think well of herself, put herself first."

"Some women's challenge is just to come in the door."

"Each woman will have a different challenge."

"Challenging someone to think well of herself is support."

"It's needs-based: facilitators read their group constantly, figuring out ways to challenge and support and encourage within that space."

"There's an element of taking each woman as she comes, and her set of circumstances."

"It increases a woman's self-confidence to have control over something like pace because many of the women have very little control over anything else, or may not have been asked the question 'what would you like, what time would you like to have your break?' It can be the beginning of helping somebody think, what do I want? The process of (working out) where do I fit into the world, or what I want counts. When somebody says to you, maybe I can't make it until such a time, something changes for you, because it says I matter, my presence here matters, something has changed to accommodate me, so I matter."

"It's the nothing stuff, but it's huge."

A care-full model of practice became visible, enabling the organisation to redefine its mission of social change: it was the provision of the feminist space and a feminist learning culture that enabled significant habitus changes for participants by enabling them take on a provisional habitus (Bourdieu 2001) that kept oppressive norms by gender, class, and race at bay. The organisation could have no definite progression goal that would be achieved, such as the education of women to become feminist activists: the organisation's role was to provide a culture that enabled a provisional habitus to be experienced. The organisation's existence and learning culture is the social change.

\section{The Second Research Project: "Not Like School"}

Previous to this research, NALA invited adult literacy organisations to nominate tutors to showcase good practice in working with adults, and each case study provided background information on their adult literacy service, information about the tutor, the tutor's understanding of literacy/numeracy, how they work with the learners' goals and needs, preparing resources, working with groups, and their approaches to teaching and learning. Interviews with adult literacy and numeracy tutors formed the series of case studies of practice (Byrne and Sellers 2013; Byrne et al. 2014, 
2016), providing rich accounts of good practice in teaching numeracy, English as a Second Language (ESOL), reading, writing, and computer skills.

The revised Guidelines for Good Adult Literacy Practice (McHugh and Dolan 2012) provided a framework for the further examination of the accounts in the two most recent case studies for what they indicated in relation to counteracting the deficit view of the adult learning by operating the wealth model of adult literacy. Using grounded theory, the data was compiled from 14 interviews with tutors to identify how they expressed the wealth model in their practice. These accounts were then organised by using the Guidelines for tutor approaches, working with the learner's goals and interests, working with different beliefs and cultures, learners' knowledge and skills, and establishing the environment for learning. The quotations that follow illustrate the wealth model in practice.

Tutor Caroline enabled adults feel welcome and settle in by saying to learners that classes will not be like school.

"It's not like school, 'sit down there', 'shut up and do as you're told'. You will be interacting with the other people, you will have strengths, they will have strengths" (Caroline cited in O'Grady and Byrne 2018, p. 44).

Tutors Eleanor, Peter, and Andrew established how the process can be different by asking the group of learners what will be useful to them:

"We always say to them, 'what do you want from the class? Have you any ideas for the next few weeks of any topics that you might like to cover that are going to be useful outside in the real world?'" (Eleanor, Peter and Andrew cited in O'Grady and Byrne 2018, p. 35).

Certification opportunities also show how different it can be:

"People do see the value that you get a Level 3 (NFQ award equivalent to lower second-level) without the big exam just by preparing a folder"(Margaret, cited in O'Grady and Byrne 2018, p. 33).

Getting to know the learners and decide on topics and material that will be suitable is an ongoing process:

"The more time we spend together, the more confidence I have that I can cater to everybody's needs. The longer you are together, (the better) you can gauge. So, the first couple of classes are the hardest, and once you get a feel for the capabilities of each person, it does get easier" (Caroline, cited in O'Grady and Byrne 2018, p. 32).

Clare checked a group's prior knowledge "before we would do any reading" (Clare, cited in O'Grady and Byrne 2018, p. 32).

Sorcha explained how she made abstract concepts become real:

"Maths is related to all parts of life, so it's an easy one, you can always relate it to what they're doing every day, or to their personal interests. You've got to link it to something they already understand, or that they are familiar with in their own life" (Sorcha, cited in O'Grady and Byrne 2018, p. 33).

Sorcha identified how understanding a new concept can be an opportunity for the learner to reframe their own experience:

"They start relating it to what they were trying to learn in school and that they're 'oh, so that's what it means'. And they also start relating it to what they are doing every day. It makes people realise 'you know, actually it wasn't me that was the problem, that it was either my situation or my learning circumstances, or that I had to leave school early, or that the system didn't suit my learning style'" (Sorcha, cited in O'Grady and Byrne 2018, p. 36).

Tutors see that the learner's existing knowledge will enable them help their peers. For example: 
"They get a great kick of explaining stuff to you, and it helps them as well [recognise] their thought process about how they would explain it, and it helps with their vocabulary" (Fiona cited in O'Grady and Byrne 2018, p. 18).

The learner's home environment is also taken into account and respected:

"It is a huge commitment to say you're going to do anything on the same day every week for 40 weeks of the year" (Margaret, cited in O'Grady and Byrne 2018, p. 37).

Margaret is always willing to respond to a learner:

"Sometimes they will come in with something and it is an immediate need that must be dealt with" (ibid, cited in O'Grady and Byrne 2018, p. 35).

The tutor's respect for the life experience of the learner means being selective and critical about resources to be provided:

"They're overwhelmed with information and they can get a lot of it online, so that is where we try to enhance computer skills to make it relevant to them" (Elaine, cited in O'Grady and Byrne 2018, p. 32).

This attention to a process model of curriculum allows a learner with an internalised negative view of formal education to transform their sense of themselves as a knower and learner, and revise their ideas about what formal education can be like and what it can do for them.

\section{The Connection}

The wealth model of adult literacy allows the learner to reframe their earlier experiences of education; skills are acquired for functional purposes, but are extended to understanding society, which is the critical literacy aspect of practice. Reading the world is possible once concepts are understood, and they are understood by relating concepts to practical examples in the learner's own world. The women's community education approach is similar, in that the purpose of feminist groupwork is speaking one's mind, hearing how similar one's experiences as a working-class woman are, and thereby seeing those personal experiences as political, i.e. changeable and explainable in terms of societal structures and power. The individual's agency to extend practice further into actively working for social change is not under the control of a facilitator, tutor, or organisation. They can only provide the concepts, space, and skills to enable a reading of the world in terms of power, structure, and agency.

The educator is a facilitator, not a transmitter of knowledge to be regurgitated in an exam. Knowledge is to be 'really useful' in the tradition described by Thompson (2007) as the knowledge that people need to change their lives. Lovett (1975), writing from the standpoint of an adult educator in working-class communities and Belfast and Liverpool in the 1970s, stated that adults prefer to make learning personal and concrete, rather than learning for the sake of acquiring abstract knowledge that does not have much meaning in the lives of the working classes. Critical consciousness must be based in the realities of people's lives (Hooks 2000).

Gloria Watkins, writing as bell hooks, linked feminism, class, and gender in her criticism of mainstream education, especially higher education in the United States. The job of the radical educator, according to Hooks, is to enable an examination of oppressive norms and undo conditioning. I think of 'transgression' as the ability to stop an oppressive norm having power over the person or group, such as when students are taught 'how to listen, and how to hear one another' (Hooks 1994, p. 150). A classroom 'becomes a dynamic place where transformations in social relations are concretely actualised' (Hooks 1994, p. 195).

The unlearning required to undo conditioning and envisage a new future is considerable, and has been taken up by the arm of the women's movement that is concerned with disadvantaged groups 
and their experience of oppression, and by adult literacy tutors in terms of critical literacy. When this 'norm transgressing' phase becomes well-established, it can result in the learner or group expressing their own aims, goals, and intentions. Passivity has been replaced with a sense of agency. Both sites of adult education practice are linked by a focus on change, and the capacity of individuals to take action in their lives.

\section{Praxis in Women's Community Education and Adult Literacy}

Fitzsimons (2017) researched community education workers in order to identify practice in resisting neoliberalism. She stated that workers reflect either a humanist or radical educational philosophy. While humanists may promote individual change, and radicals may promote social change, both achieve change by a teaching approach that is true to their philosophy. Fitzsimons provides illustrations of how she resists neoliberalism in her own teaching, even when this teaching is to a predesigned curriculum aimed at a further education qualification.

The two research projects and Fitzsimon's own research provide evidence of agency in action: the agency of an organisation, the agency of a practitioner/researcher, and the agency of literacy tutors. Ryan (1999) reminded us that our influence as adult educators comes from our philosophical position, and it is our values that direct our decisions about the teaching and learning process, whether it is feminist pedagogy, critical literacy, or radical adult education. Our philosophy influences both how we teach, and what we teach. To achieve change, especially political change, the educator needs to be politicised.

Fitzsimons (2017) calls on educators to 'recolonise the cracks', reminding us that it is the margins where these fields of practice originated in the Republic of Ireland. The mainstreaming of further education and the state's agenda of lifelong learning for the labour market is individualistic rather than enabling collective action for social change. New layers of accountability may make us feel that we are being co-opted and worn down by business processes, but resistance to neoliberal hegemonic processes exists, whether through overt social analysis in women's community education groups, critical literacy and the wealth model operating in the adult literacy classroom, or through organisations and tutors reflecting on practices in the learning and teaching relationship.

The women's community education organisation reconceptualised its mission as the existence of a space that puts the educational needs of working-class women at the centre, and a democratic and participative learning culture that provides a provisional habitus that may become permanent. The extent to which participants become "agents of change in their own community and in wider society" (Connolly 2008, p. 17) remains outside of the control of the organisations and its facilitators. Agency can only be encouraged, but how the agency is used cannot be mandatory. Adult literacy tutors operating within the wealth model and the Guidelines for Good Practice also enable adults interpret their experiences "in social and cultural terms, rather than individualistic or private ones" (Connolly 2008, p. 7).

\section{Conclusions}

My involvement in the research in the two sites of women's community education and adult literacy showed me that both are inspired by the same Freirean ideas; both fields of practice are concerned with emancipatory pedagogies and the broad view of critical literacy. Both create safe spaces for adult learners to reflect on their lives in a period of change, and relate new information to their own needs. The women's community education approach has relied on feminist groupwork from the outset to enable dialogue and reflection; adult literacy tuition in groups has created new opportunities for literacy tutors to extend and accelerate critical literacy based on a wealth model of adult education.

These research reports are examples of how hegemonic neoliberal ideas and agendas are resisted by organisations and individual tutors in the face of new policy contexts and demands. The social justice aim of adult education is surviving in community education because providers, facilitators, 
and tutors have autonomy to choose their model of practice that is rooted in the social practices and lived experiences of the participants. If the dominant neoliberal education system has its own hidden curriculum of individualised education, so too the social model of community education has a hidden curriculum that can counteract how education made working-class men and women feel silenced or powerless. It may prove to be the best resistance yet.

Funding: This research received no external funding.

Conflicts of Interest: The author declares no conflict of interest.

\section{References}

Bourdieu, Pierre. 2001. Masculine Domination. Cambridge: Polity Press.

Breen, Richard, Damian Hannan, David Rottman, and Christopher Whelan. 1990. Understanding Contemporary Ireland: State, Class and Development in the Republic of Ireland. Basingstoke: Gill and Macmillan.

Byrne, Tina, and Daniel Sellers. 2013. What Really Counts: Case Studies of Adult Numeracy in Practice in Ireland. Dublin: NALA.

Byrne, Tina, Maeve O'Grady, and Eilish Roche. 2014. Read All about It: Case Studies of Teaching Reading to Adults in Ireland. Dublin: NALA.

Byrne, Tina, Maeve O'Grady, and Eilish Roche. 2016. Meeting the Challenge: Strategies for Motivating Learners in Adult Education in Ireland. Dublin: NALA.

Connolly, Bríd. 1997. 'Women in Community Education and Development-Liberation or Domestication'. In Women and Irish Society: A Sociological Reader. Edited by Anne Byrne and Leonard Madeleine. Belfast: Beyond the Pale Publications, pp. 40-58.

Connolly, Bríd. 2008. Adult Learning in Groups. Maidenhead: Open University Press.

Crowther, Jim, and Lyn Tett. 2011. 'Critical and social literacy practices from the Scottish adult literacy experience: Resisting deficit approaches to learning'. In Literacy. Oxford: Blackwell Publishing, pp. 134-40.

Curry, John. 2003. Irish Social Services, 4th ed.IPA: Dublin.

Drudy, Sheelagh, and Kathleen Lynch. 1993. Schools and Society in Ireland. Dublin: Gill and Macmillan.

Finger, Matthias, and José Manuel Asún. 2001. Adult Education at the Crossroads: Learning Our Way out. London: Zed Books.

Fitzsimons, Camilla. 2017. Community Education and Neoliberalism: Philosophies, Practices and Policies in Ireland. London: Palgrave Macmillan.

Freire, Paulo. 1970. Pedagogy of the Oppressed. Harmondsworth: Penguin.

Government of Ireland. 2000. Learning for Life: White Paper on Adult Education; Dublin: Government Publications.

Hamilton, Mary, Catherine Macrae, and Lyn Tett. 2001. 'Powerful literacies: The policy context'. In Powerful Literacies. Edited by Jim Crowther, Mary Hamilton and Lyn Tett. Leicester: NIACE.

Hooks, Bell. 1994. Teaching to Transgress: Education as the Practice of Freedom. London: Routledge.

Hooks, Bell. 2000. Where We Stand: Class Matters. London: Routledge.

Inglis, Tom. 1994. 'Women and the Struggle for Adult Daytime Education in Ireland'. Studies in the Education of Adults 26: 50-66. [CrossRef]

Kelly, Mary B. 1994. Can You Credit It: Implications of Accreditation for Learners and Groups in the Community Sector. Dublin: Combat Poverty Agency.

Lovett, Tom. 1975. Adult Education, Community Development and the Working Class. London: Ward Lock.

Lynch, Kathleen. 2013. 'Equality as Rhetoric: The Careless State of Ireland'. Paper presented to the MacGill Summer School, Glenties, Ireland, July 31.

Lynch, Kathleen, Bernie Grummel, and Dympna Devine. 2012. The New Managerialism in Education: Commercialization, Carelessness and Gender. London: PalgraveMacmillan.

McGuinness, Seamus, Adele Bergin, Eilish Kelly, Selina McCoy, Emer Smyth, Adele Whelan, and Joanne Banks. 2014. Further Education and Training in Ireland: Past, Present and Future. Research Series No. 35. Dublin: ESRI.

McHugh, Helen, and Fergus Dolan, eds. 2012. Guidelines for Good Adult Literacy Work. Dublin: NALA.

Merrill, Barbara, and Andreas Fejes. 2018. 'Editorial: Intersectionality and Adult Education. The European Journal for Adult Educational Research 9: 7-11. [CrossRef] 
Mulvey, Chris. 1991. Report on the Department of Social Welfare's Grants Scheme for Locally based Women's Groups. Dublin: The Stationery Office.

Murray, Michael, Bernie Grummel, and Anne Ryan, eds. 2014. Further Education E Training: History, Politics and Practice. Maynooth: MACE Press, pp. 169-76.

NALA. 2008. Getting Started in Adult Literacy and Numeracy: A Tutor Training Resource Pack. Dublin: NALA.

O'Grady, Maeve. 2018. An institutional ethnography of a feminist organization: A study of community education in Ireland. RELA European Journal for Research on the Education and Learning of Adults 9: 29-44. [CrossRef]

O'Grady, Maeve, and Tina Byrne. 2018. The Wealth Model in Adult Literacy. Dublin: NALA.

Papen, Uta. 2005. Adult Literacy as Social Practice: More Than Skills. Abingdon: Routledge.

Ryan, Anne B. 1999. 'Sources for a politicised practice of women's personal development education'. In Women and Education in Ireland. Edited by Bríd Connolly and Anne B. Ryan. Maynooth: MACE, pp. 11-30.

Ryan, Anne. 2014. 'Conclusion: Further Education and Training: The Trojan Horse'. In Further Education $\mathcal{E}$ Training: History, Politics and Practice. Edited by Michael Murray, Bernie Grummel and Anne Ryan. Maynooth: MACE Press, pp. 169-76.

Smith, Dorothy. 2005. Institutional Ethnography: A Sociology for People. Lanham: AltaMira Press.

Solas. 2014. Further Education and Training Strategy. Dublin: Government Publications Office.

Thompson, Jane. 2007. “Really Useful Knowledge': Linking Theory and Practice'. In Radical Learning for Liberation 2. Edited by Bríd Connolly Ted Fleming, David McCormack and Anne Ryan. Maynooth: MACE, pp. 25-36.

Trow, Martin. 1974. Problems in the Transition from Elite to Mass Higher Education. Paris: Organisation for Economic Co-Operation and Development (OECD), pp. 51-101.

www.QQI.ie and Access, Transfer and Progression. n.d. Available online: https:/ /www.qqi.ie/Articles/Pages / Access,-Transfer-and-Progression.aspx (accessed on 6 December 2018).

(C) 2018 by the author. Licensee MDPI, Basel, Switzerland. This article is an open access article distributed under the terms and conditions of the Creative Commons Attribution (CC BY) license (http:/ / creativecommons.org/licenses/by/4.0/). 